\title{
BMJ Open National estimation of children in residential care institutions in Cambodia: a modelling study
}

\author{
Lindsay Stark, ${ }^{1}$ Beth L Rubenstein, ${ }^{1,2}$ Kimchoeun Pak, ${ }^{3}$ Sok Kosal ${ }^{4}$
}

To cite: Stark L,

Rubenstein BL, Pak K, et al. National estimation of children in residential care institutions in Cambodia: a modelling study. BMJ Open 2017;7:e013888.

doi:10.1136/bmjopen-2016013888

- Prepublication history for this paper is available online. To view these files please visit the journal online (http://dx.doi.org/10.1136/ bmjopen-2016-013888).

Received 16 August 2016 Revised 12 December 2016 Accepted 14 December 2016

CrossMark

For numbered affiliations see end of article.

Correspondence to Dr Lindsay Stark; Is2302@ cumc.columbia.edu

\section{ABSTRACT}

Objectives: The primary objective of this study was to collect baseline data on the number of children living in residential care institutions in Cambodia. The secondary objective was to describe the characteristics of the children (eg, age, sex, duration of stay, education and health). The data were intended to guide recent efforts by the Government of Cambodia to reduce the number of children living in residential care institutions and increase the number of children growing up in supportive family environments.

Setting: Data were collected in Cambodia across 24 sites at the commune level. Communesadministrative divisions roughly equivalent to counties - were selected by the National Institute of Statistics using a two-stage sampling method.

Design: Government lists and key informant interviews were used to construct a complete roster of institutions across the 24 communes. All identified institutions were visited to count the number of children and gather data on their basic characteristics. The rate of children in residential care in the selected communes was calculated as a percentage of total population using a Poisson model. This rate was applied to all districts in Cambodia with at least one reported residential care institution.

Participants: A total of 3588 children were counted across 122 institutions. A child living in a residential care institution was defined as anyone under the age of 18 years who was sleeping in the institution for at least four nights per week during the data collection period.

Results: There are an estimated 48775 children living in residential care institutions in Cambodia. The vast majority of children have a living parent and are school-aged. More than half are between 13 and 17 years of age.

Conclusions: Nearly 1 of every 100 children in Cambodia is living in residential care. This raises substantial concerns for child health, protection and national development.

\section{INTRODUCTION}

There is increasing international mobilisation around the importance of family care for optimal child health and development. ${ }^{12}$ In many instances, this mobilisation has been

\section{Strengths and limitations of this study}

A major strength of this study is that, to the best of our knowledge, this is the first time nonadministrative national survey data on the number of children in residential care have been collected in a low-income or middle-income country.

- The study protocol also included clear inclusion and exclusion criteria and the procedures for identifying institutions through local key informant interviews were extremely thorough.

- An additional strength of this study was the fact that the number of children in each institution was determined by triangulating multiple sources (directors' reports, registry data and night counts).

- The statistical model used for the national estimate assumes that the trends detected within the 24 sampled communes are applicable to all districts with at least one reported residential care institution.

- This study is limited by reliance on self-reported measurements of children's characteristics.

in response to the rapid expansion of residential care institutions in many low income and middle income countries (LMICs). In the USA and much of Western Europe, children were de-institutionalised in waves starting in the 1940s, but this trend has not yet been realised in much of the Global South. ${ }^{3}$

Concerns about the harmful effects of residential care institutions are primarily based on a series of well-designed research studies from Russia and Romania where tens of thousands of children were institutionalised at very young ages during the 1980 s and 1990s. ${ }^{4-8}$ In these countries, children living in residential care institutions were found to be severely malnourished, socially and emotionally deprived, and intellectually deficient. However, in Romania, children who were removed from residential care institutions and placed into highly professional foster care before 24 months largely recovered after 
placement. Dramatic improvements were observed for the de-institutionalised children on multiple measures, including scans of brain activity. ${ }^{8}$ For children who remained in residential care institutions, the damage was generally irreparable and reverberated into adulthood. ${ }^{7}$

Much less is known about the developmental trajectories of institutionalised children in other regions of the world where entry into residential care tends to happen at older ages. Some reports have suggested that older children also face serious risks from institutionalisation including physical and sexual abuse, trafficking and economic exploitation, but a 3-year longitudinal study from six countries found that older institutionalised children scored better than or equivalent to their community counterparts in terms of growth, physical health and cognitive abilities. ${ }^{9-13}$ In short, the impact of institutionalisation at older ages on long-term development is not well established and further research is needed to explore the potential effects of children who enter institutions at school age or later. ${ }^{3}$

Yet regardless of the comparative outcomes for different ages of children, governments have an ethical imperative to safeguard children in residential care institutions and to track information about the magnitude and characteristics of this segment of the population. Knowledge about children in residential care is necessary to formulate responsive policies and services, mobilise resources and foster accountability. Currently, however, where data on children in residential care do exist, it is highly fragmented and of dubious quality.

Recognising this gap, the Royal Government of Cambodia recently conducted a national estimation of children in residential care institutions in partnership with Columbia University and Moulathan Consulting. The goal of the exercise was to generate baseline data to track reductions in the number of children in residential care over time. A rigorous estimation approach was adopted in order to avoid the time and cost involved in visiting every institution in Cambodia and to allow for replication in other resource-limited settings. This manuscript describes the methods, findings and implications of the estimation. To the authors' knowledge, Cambodia is the first LMIC to actively conduct a national estimation of children in residential care institutions that goes beyond the summary of routine administrative data.

\section{METHODS}

An overview of the methods described in the following sections is presented in figure 1 .

\section{Sampling of institutions}

Data were collected at the commune level across 24 sites in Cambodia during June and July 2015. Communesadministrative divisions roughly equivalent to countieswere selected by the National Institute of Statistics (NIS) using a two-stage sampling method. Eleven of 24 provinces in Cambodia were first selected using stratified random sampling. Probability-proportionate-to-size sampling was then used to select a total of 24 communes across the 11 selected provinces, using residential care data from the Ministry of Social Affairs, Veterans and Youth Rehabilitation (MoSVY), and UNICEF Cambodia. Communes with zero children reported in residential care institutions were not eligible for selection.

Within communes, data collectors identified all residential care institutions in the commune boundaries by checking MoSVY's records and conducting key informant interviews to identify institutions potentially in existing records. Data collectors interviewed every village chief from selected communes, as well as a smaller number of non-governmental (NGO) staff, health providers and other community members in the target area. The data collectors then visited all identified residential care institutions.

\section{Study design}

The study was designed to triangulate information from multiple sources to cross-verify the number of children living in each facility. First, data collectors visited each identified institution during the day and sought consent to speak with staff and review the registry of children residing there. Data collectors explained to staff that they were only interested in counting children who were currently sleeping in the institution. Children who received daytime services or attended school at the institution, but slept in the community, were not counted.

During this daytime visit, data collectors also interviewed the staff to determine basic institution characteristics (eg, institution type, registration status, number of paid and volunteer staff). In addition to self-reported data on whether or not the institution had a Memorandum of Understanding (MOU) with MoSVY ('institutions self-reporting MoSVY registration'), a variable was added during analysis to capture whether or not the institution was listed in MoSVY's 2014 Residential Care Inspection Report. This inspection report included the names and locations of all residential care institutions visited by MoSVY in 2014 (the most recent year for which data were available).

On the same day as the first daytime visit, the data collectors returned to each institution at dinnertime to observe the number of children on the premises. The dinnertime count was compared to the daytime registry count. Although data collectors had informed daytime staff that they would be returning again for an evening visit within the coming month, the exact date of the evening visit was not disclosed in order to prevent staff from potentially bringing in children who were not normally in their overnight care in order to artificially inflate their numbers. During the evening visit, data collectors recorded the number of children at dinner. Then, for a random subset of $20 \%$ of the children from the registry, data collectors verified that these children's 


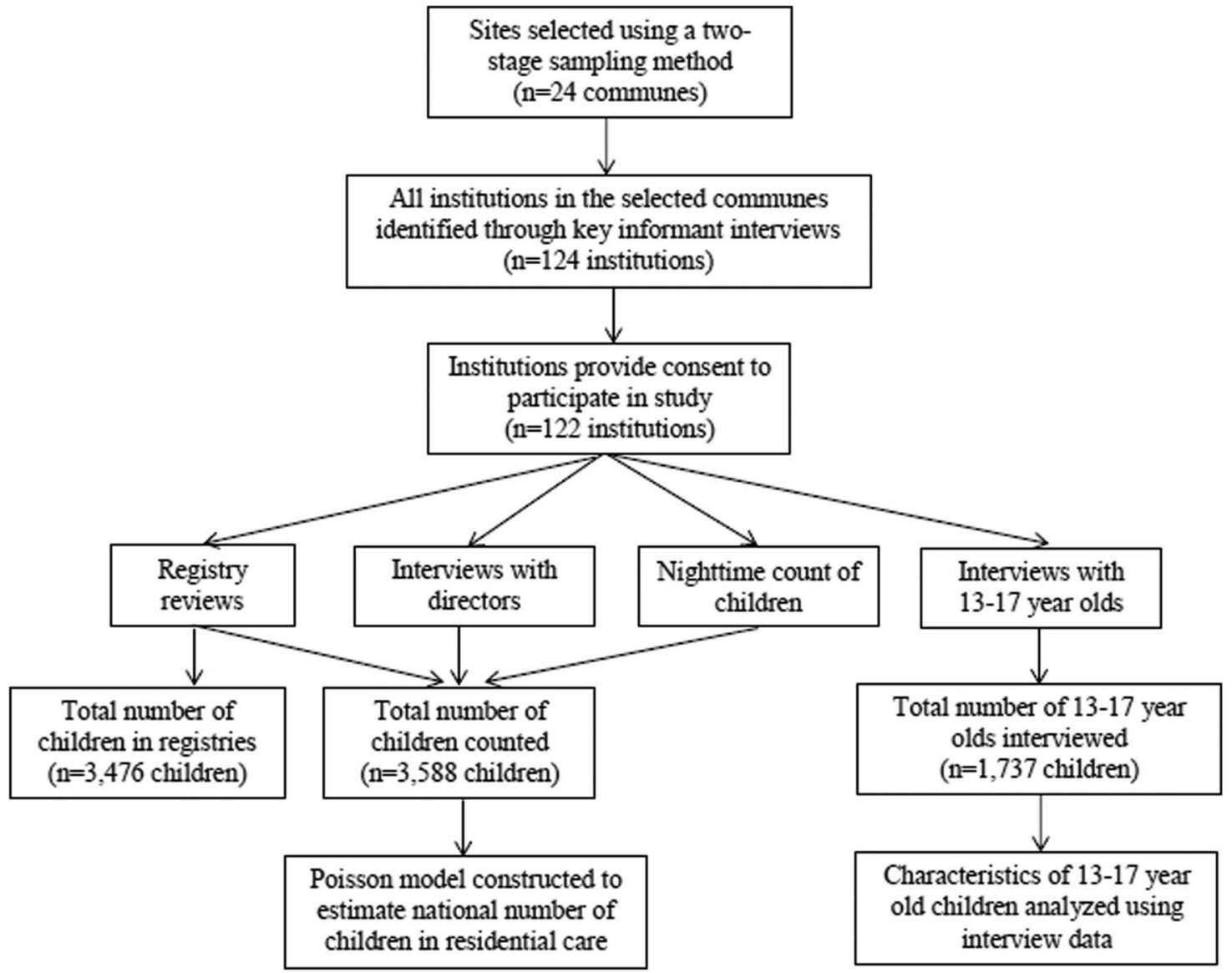

Figure 1 Methods overview.

names, sexes and ages matched the original records by selecting a random number $\mathrm{n}$ between one and five (generated electronically), and then reading aloud the name of the child listed on the nth line of the registry. If this child was present at dinner, she or he would raise their hand and the data collector would verify whether the child's age and sex matched those listed in the registry. This process was then repeated for every fifth child in the registry.

Finally, data collectors conducted individual interviews with all children aged 13-17 years who lived in the visited institution and consented to the interview process. These individual interviews captured information about the children's background and orphan status, reasons for institutionalisation, school attendance, involvement with institutional fundraising and health and well-being. To assess literacy, children were also asked to read a few simple sentences in Khmer. The minimum age of 13 years for interviews was determined based on extensive conversations with social workers in Cambodia who advised that 13 years was the minimum age at which children could meaningfully participate in the consent process. This determination is consistent with international guidelines on research with minors. ${ }^{14} 15$

All interviews were conducted in private and no identifying information was recorded. As part of the formal consent process, the researcher explained the study purpose and told the children that their answers would be confidential and would not affect the care they received. Potential participants were also told that they had the right to refuse to be interviewed and would not face any consequences for their decision. All of this information was also reiterated on the written consent form. All participants were given a copy of the consent form for their records.

All data were collected electronically using the FieldTask application for smart phones. Field Task [program]. SMAP Consulting, 2015.

\section{Inclusion criteria for institutions}

A residential care institution was defined as any facility where children live and where there is at least one fulltime staff member (paid or volunteer) whose primary purpose is to provide long-term care for children. Long-term care was operationalised to refer to situations in which most of the children lived in the institution for 6 months or longer, and for at least four nights per week. These criteria follow the definition of residential care provided by MoSVY and other sources. ${ }^{16}$ For the purpose of this study, institutions were included regardless of the number of children in their care. Residential care institutions that self-identified as specialised institutions (eg, caring for children with disabilities, caring for children with HIV/AIDS, drug treatment centres) were 
included in the study if they met the general definition stated above.

A child living in a residential care institution was defined as anyone under the age of 18 years who was sleeping in the institution for at least four nights per week during the data collection period.

\section{Statistical analysis}

To estimate the total number of children in residential care at the national level, final counts from each institution were summed for each sampled commune. A Poisson regression model was then constructed to calculate the rate of children in residential care as a percentage of the total commune population. The Poisson model was corrected for over-dispersion, and the exponentiated $\beta$ was applied to all districts in Cambodia with at least one reported residential care institution. This calculation yielded a national estimate. Data on population and residential care institutions were taken from the 2014 commune database, a compilation of demographic indicators reported by community representatives on an annual basis.

Descriptive statistics were calculated in SAS V.9.4 (SAS Institute. SAS Institute version 9.4: Cary NC, 2013). For institution characteristics, data were generated from interviews with institution staff. For characteristics of all children, including children younger than 13 years of age, data were generated from institution registries. For additional characteristics of children between 13 and 17 years of age, data were generated from individual interviews with the participating children. All characteristics of children were disaggregated by child sex. $\mathrm{p}$ Values for differences between male and female children were determined using t-tests and $\chi^{2}$ tests.

\section{Role of the funding source}

Financial support was provided by Advancing Partners and Communities (agreement number APC-GM-0060), a 5-year cooperative agreement funded by the US. Agency for International Development under Agreement number AID-OAA-A-12-00047. The sponsor of the study had no role in study design, data collection, data analysis, data interpretation or writing of the report. The corresponding author had full access to all the data in the study and had final responsibility for the decision to submit for publication.

\section{RESULTS}

Data collectors visited 124 residential care institutions in the 24 sentinel communes. Of these institutions, 122 consented to participate in the study, yielding a participation rate of $98.4 \%$. A total of 3588 children were counted across the 122 consenting institutions, representing a prevalence of $0.69 \%$ of the total population in the 24 communes where data were collected. Applying the exponentiated $\beta$ from the Poisson model to the population of all districts in Cambodia with at least one residential care institution reported in the commune database, it is estimated that there are 48775 children living in residential care institutions in Cambodia. This is in comparison to the previous government estimate of 11453 children living in residential care institutions in Cambodia. ${ }^{17}$ This estimation, as well as additional institutional characteristics, are reported below (see table 1). Numbers of staff, registration status and primary purpose of the institution are all based on self-report from staff.

Child characteristics were analysed using the data from the institution registries (see table 2). Although 3588 children were counted in residential care, only 3476 children were recorded in the registries. This difference was primarily driven by five institutions that did not provide registries ( $\mathrm{n}=79$ children $)$. The small remaining difference was most likely due to outdated registries that had not yet recorded recent arrivals. Characteristics of the 112 children who were not recorded in the registries are unknown.

Among the registered children, there were significantly more boys, compared to girls living in residential care. The vast majority of children were school-aged, with more than half of all children between 13 and 17 years of age. The mean reported age of entry into residential care was about 8 years for both boys and girls, but this statistic could only be calculated for $27 \%$ of registered children because only 27 of 122 institutions included age of intake in their registries. The institutions that included age of intake tended to be slightly larger than the institutions in the overall sample (median number of children per institution=28, compared to 21 for the overall sample).

Individual interviews were conducted with 1737 children between 13 and 17 years of age to gather a more in-depth understanding of children's circumstances (see table 3). Almost $80 \%$ of children reported at least one

\begin{tabular}{|c|c|}
\hline Total number of children (national estimate) & 48775 \\
\hline Median number of children/institution (IQR* & $21(26.50)$ \\
\hline Staff: child ratio, paid staff only & $1: 6.46$ \\
\hline Staff: child ratio, including volunteers & $1: 5.47$ \\
\hline \multicolumn{2}{|l|}{ MoSVY† oversight } \\
\hline $\begin{array}{l}\text { Percentage of institutions self-reporting } \\
\text { MoSVY† registration }\end{array}$ & 68.03 \\
\hline $\begin{array}{l}\text { Percentage of institutions inspected by } \\
\text { MoSVY†, } 2014\end{array}$ & 29.51 \\
\hline \multicolumn{2}{|l|}{ Primary purpose of institution } \\
\hline For children to live & $33.61 \%$ \\
\hline For children to study & $45.08 \%$ \\
\hline To care for the sick/disabled & $4.92 \%$ \\
\hline Religious institution & $4.92 \%$ \\
\hline Other & $6.56 \%$ \\
\hline
\end{tabular}


Table 2 Child characteristics (all children, from registries. $n=3476$ )

\begin{tabular}{|c|c|c|c|c|}
\hline & All & Male & Female & p Value \\
\hline Sex & - & $57.03 \%$ & $42.97 \%$ & $<0.0001$ \\
\hline \multicolumn{5}{|l|}{ Missing=31 children } \\
\hline \multicolumn{5}{|l|}{ Age } \\
\hline$<5$ years & $3.71 \%$ & $3.61 \%$ & $3.92 \%$ & 0.1371 \\
\hline $5-<9$ years & $13.58 \%$ & $14.45 \%$ & $12.51 \%$ & \\
\hline $9-<13$ years & $31.39 \%$ & $32.16 \%$ & $30.29 \%$ & \\
\hline $13-<18$ years & $51.29 \%$ & $49.77 \%$ & $53.28 \%$ & \\
\hline \multicolumn{5}{|l|}{ Missing $=32$ children } \\
\hline Mean age, years $\left(\mathrm{SD}^{\star}\right)$ & $12.35(3.60)$ & $12.25(3.64)$ & $12.46(3.55)$ & 0.0910 \\
\hline \multicolumn{5}{|l|}{ Missing=32 children } \\
\hline Mean age of entry, years $\left(\mathrm{SD}^{*}\right)$ & $8.23(3.84)$ & $8.15(4.01)$ & $8.33(3.58)$ & 0.4853 \\
\hline Missing=2554 children & & & & \\
\hline
\end{tabular}

living parent, and parental status did not vary significantly by child sex. Among children with at least one living parent, almost half of the children reported that their parent(s) lived in the same province as the residential care institution. Girls were significantly more likely than boys to have a parent in the same province $(\mathrm{OR}=1.52, \mathrm{p}$ value $=0.0001)$. In terms of the primary reason that children were separated from their parents, $75 \%$ of children cited either escape from poverty or educational opportunities. Girls were significantly more likely than boys to say that they had been separated to pursue educational opportunities $(\mathrm{OR}=1.34$, $\mathrm{p}$ value $=0.0034)$.

School attendance and literacy were high among boys and girls, though girls performed slightly better than boys on both measures ( $p$ values $=0.0242$ and $<0.0001$, respectively). Nearly one-third of children reported being involved in performances or other fundraisers, such as dances or craft-making for tourists, to support the institution and this was more common for girls than for boys $(\mathrm{OR}=1.42$, $\mathrm{p}$ value $=0.0035)$. However, involvement in fundraising activities and other work or chores did not reportedly interfere with children's ability to attend school or get sufficient sleep. Most children reported feeling safe and having contact with adults they could trust.

\section{DISCUSSION}

\section{Methodological implications}

As the first known effort to devise a national estimate of children in residential care in a low-resource setting using survey data, the study demonstrated multiple methodological strengths which will provide useful learning for future work in Cambodia and beyond. The study protocol included clear inclusion and exclusion criteria, both for residential care institutions and children living in residential care institutions, and the procedures for identifying institutions through local key informant interviews were extremely thorough. Once the residential care institutions were identified, data collectors paid careful attention to getting an accurate count of the children living there. Many institution staff would initially cite a large number of children in residence, but further discussions with staff revealed that the majority of these children were only receiving daytime services (eg, schooling). The tendency of institutional staff to over-report children was confirmed by the registry reviews and night counts, which found that the number of children in residence matched the staff's estimates only after staff were specifically asked to exclude children receiving daytime services.

The strengths of this study are in contrast to the methods used to gather administrative data for previous counts of children in residential care in Cambodia. In particular, it is likely that the active approach to finding institutions described here contributed substantially to the larger total estimate of children in residential care in Cambodia, compared to estimates from administrative data. During the course of data collection, local officials noted that, at the commune level, the number of enumerators for this study was much higher than for other counts. The officials speculated that this staffing advantage may have facilitated more robust measurement. Further, by including institutions that met inclusion criteria but did not necessarily self-identify as residential care institutions, this study captured children who may be obscured by processes that depend on self-reporting.

As with any method, the statistical model to estimate the number of children at the national level is not without limitations. The model assumes that the trends detected within the 24 sampled communes are applicable to all districts with at least one reported residential care institution, as reflected in the commune database. This assumption is strengthened by the fact that communes were selected using probability-proportionate-to-size sampling. Given the lack of quality control in the MoSVY and UNICEF data, however, which formed the sampling frame, the sampled communes are unlikely to be fully representative of Cambodia.

In addition, since the calculated rate was only applied to districts with reported institutions as listed in the commune database, it is likely that the number of children in residential care in Cambodia has been underestimated. 
Table 3 Child characteristics (13-17 years, from interviews, $n=1737$ )

\begin{tabular}{|c|c|c|c|c|}
\hline & All (\%) & Male (\%) & Female (\%) & p Value \\
\hline \multicolumn{5}{|l|}{ Parental status } \\
\hline Both alive & 43.64 & 43.45 & 43.85 & \multirow[t]{5}{*}{0.1912} \\
\hline Only mother alive & 22.74 & 21.24 & 24.47 & \\
\hline Only father alive & 12.15 & 11.80 & 12.55 & \\
\hline Both deceased & 18.54 & 20.39 & 16.40 & \\
\hline Do not know & 2.94 & 3.11 & 2.73 & \\
\hline \multicolumn{5}{|l|}{ Parental location } \\
\hline Same commune & 5.28 & 5.33 & 5.22 & \multirow[t]{6}{*}{0.0024} \\
\hline Same district & 6.89 & 5.47 & 8.45 & \\
\hline Same province & 33.87 & 30.29 & 37.79 & \\
\hline Different province & 45.75 & 50.77 & 40.25 & \\
\hline Different country & 5.94 & 6.03 & 5.84 & \\
\hline Do not know & 2.27 & 2.10 & 2.46 & \\
\hline \multicolumn{5}{|l|}{ Primary reason for separation } \\
\hline Escape from poverty & 38.86 & 39.06 & 38.63 & \multirow[t]{7}{*}{0.0086} \\
\hline Educational opportunities & 36.85 & 33.69 & 40.50 & \\
\hline Parental death & 9.44 & 10.62 & 8.07 & \\
\hline Parental marriage & 1.67 & 1.82 & 1.49 & \\
\hline Escape from abuse & 1.32 & 0.97 & 1.74 & \\
\hline Other & 10.13 & 11.59 & 8.45 & \\
\hline Do not know & 1.61 & 2.04 & 1.12 & \\
\hline \multicolumn{5}{|l|}{ School attendance } \\
\hline Every day & 95.74 & 94.64 & 97.02 & \multirow[t]{4}{*}{0.0242} \\
\hline A few days a week & 0.81 & 1.29 & 0.25 & \\
\hline Once in a while & 0.12 & 0.21 & 0.00 & \\
\hline Not in school & 3.34 & 3.86 & 2.73 & \\
\hline \multicolumn{5}{|l|}{ Literacy } \\
\hline Able to read whole sentence & 86.18 & 82.73 & 90.19 & \multirow[t]{5}{*}{$<0.0001$} \\
\hline Able to read parts of sentence & 8.64 & 11.59 & 5.22 & \\
\hline Cannot read at all & 3.86 & 3.97 & 3.73 & \\
\hline Blind/visually impaired & 0.86 & 1.07 & 0.62 & \\
\hline Other & 0.46 & 0.64 & 0.25 & \\
\hline \multicolumn{5}{|c|}{ Involved in performances or other fundraisers to support the institution } \\
\hline Yes & 31.15 & 27.68 & 35.16 & 0.0035 \\
\hline \multicolumn{5}{|c|}{ Sick in the past 30 days (unable to work/study/do chores) } \\
\hline Yes & 16.58 & 16.09 & 17.14 & 0.5579 \\
\hline \multicolumn{5}{|l|}{ Child feels safe where $s /$ he lives } \\
\hline Very safe & 91.48 & 91.31 & 91.68 & \multirow[t]{3}{*}{0.6361} \\
\hline Somewhat safe & 8.46 & 8.58 & 8.32 & \\
\hline Do not know & 0.06 & 0.11 & 0.00 & \\
\hline \multicolumn{5}{|c|}{ Child trusts adults with whom s/he has contact } \\
\hline A lot & 89.69 & 89.27 & 90.19 & \multirow[t]{4}{*}{0.4624} \\
\hline Somewhat & 10.02 & 10.41 & 9.57 & \\
\hline Not at all & 0.17 & 0.11 & 0.25 & \\
\hline Do not know & 0.12 & 0.21 & 0.00 & \\
\hline
\end{tabular}

The information in the commune database relies on community representatives who report on many different indicators and are not trained in understanding the specific inclusion criteria for residential care institutions. Therefore, it is likely that there are some districts with at least one residential care institution that were missed by the commune database and, by extension, the estimation.

Policy implications

NIS and partners have demonstrated that it is feasible to conduct a national estimation of children in residential care institutions in a resource-limited setting. This is an important precedent for Cambodia, as well as for other countries.

The findings reveal that the number of children living in residential care institutions in Cambodia is significantly higher than previous government estimates. According to the new estimates, nearly 1 of every 100 children in Cambodia is currently living in residential care. Additionally, nearly one-third of the institutions where these children live do not have a MOU with MoSVY, and $70 \%$ of the institutions were not inspected by MoSVY in 2014. These findings raise substantial concerns for child health, protection and national development priorities. 
When examining the profile of children living in residential care, this study reveals several important themes. First, almost all children living in residential care institutions in Cambodia are older than 5 years of age. This age distribution is consistent with our finding that the primary purpose of nearly half of the institutions is for children to study. Second, among the older children interviewed, most children have at least one living parent and stated that they were living in residential care to escape poverty and pursue educational opportunities. Conversations with residential care directors, UNICEF, MoSVY and local NGOs revealed that most children in Cambodia are under the care of their parents before they come to the institution. The proliferation of residential care institutions in Cambodia seems to reflect the lack of viable alternatives for families who struggle to provide for their children. Some people have even gone so far as to describe residential care in Cambodia as a de facto social welfare system, albeit one that has been subject to intense criticism. ${ }^{18}$

Further, the findings suggest that residential care institutions do seem to meet some of the children's needs. Among the older children, there were high levels of school attendance and literacy, low levels of reported work and illness, and high levels of reported safety and trust. Although an appropriate comparison group was not included in the study design, the interview data from older children suggested that, for some indicators, children in residential care may be doing better than their community counterparts in the lowest wealth quintiles, especially in terms of educational achievement and literacy. ${ }^{19}$ In addition, this profile is inconsistent with the systematic abuse and neglect documented among children living in residential care institutions in Russia and Romania. Findings similar to those in our study have been found in research on institutional care from Cambodia, China, Ethiopia, India, Kenya and Tanzania, and underline the need for more data from diverse settings. ${ }^{13}$ 20-22

One explanation for these findings on children's wellbeing could be related to the way in which the data were collected. With the exception of the literacy assessment, data about characteristics of 13-17-year-olds relied entirely on self-reported measurements. The interviews may have been particularly prone to biases, as children may not recall the reasons surrounding their separation from their parents at a young age. Regarding questions about school attendance, safety and trust, children may feel pressure to provide positive responses so that they or their caregivers do not face repercussions. That said, qualitative reports from data collectors indicated that, overall, most institutions projected a caring environment and that children seemed candid and well-adjusted during informal observation.

Most importantly, however, even well-intentioned residential care institutions should not serve as a substitute for a functioning child welfare system that prioritises family care. The vast majority of children in residential care institutions in Cambodia have living parents, but the current system effectively severs the family unit. Even during the two major holidays per year when many institutions allow for family visitation, the travel costs are often prohibitive, especially for the children whose parents live in another province. Complicating matters, some families perceive that their children have been legally relinquished, even if this is not necessarily the case. Primary prevention is therefore paramount. With adequate investments in social services and schools instead of institutions, more opportunities for children could be provided in their own communities and the poverty and education-related factors driving children to be separated from their families could be greatly reduced.

\section{CONCLUSION}

All children have the fundamental right to grow up in a loving and protective family environment. Cambodia and the international community have an obligation to support families so they can provide for their children, even in the face of poverty. Building effective systems in Cambodia that can serve these purposes will take significant time and resources, but it is hoped that this study will generate greater awareness of the scale and urgency of the issue. This study can also draw attention to the harsh realities that make residential care appealing to so many parents and caregivers. Implementing reforms that address these root causes is a daunting task and this manuscript can only motivate and inform the essential work of practitioners and policymakers on the ground. In the interim, the government is responsible for protecting the rights and ensuring the development and well-being of the estimated 48775 children who are currently in residential care. The government's commitment to measurably reduce the number of children in residential care is an example for other countries seeking to increase accountability towards vulnerable populations and strengthen the next generation of citizens.

\section{Author affiliations}

${ }^{1}$ Program on Forced Migration and Health, Mailman School of Public Health, Columbia University, New York City, New York, USA

${ }^{2}$ Department of Epidemiology, Mailman School of Public Health, Columbia University, New York City, New York, USA

${ }^{3}$ Moulathan Consulting, Phnom Penh, Cambodia

${ }^{4}$ National Institute of Statistics, Ministry of Planning, Royal Government of Cambodia, Phnom Penh, Cambodia

Acknowledgements The authors would like to thank Richard Rinehart for his vision and ongoing support, H E Hang Lina for her extraordinary leadership, Gary Yu for his assistance with modelling and analysis and the two reviewers for their suggested edits. In addition, the authors would like to express special gratitude to the institutions visited and the children who participated in the study.

Contributors LS, BLR, KP and SK conceived and designed the study. BLR, KP and SK led the data collection in Cambodia. BLR led the statistical analysis. LS and BLR wrote the manuscript. KP and SK contributed important revisions to the manuscript. LS served as Principal Investigator of the study. All authors approved the final submitted version of the manuscript. 
Funding Support for this work was provided by Advancing Partners and Communities (agreement number APC-GM-0060), a 5-year cooperative agreement funded by the US. Agency for International Development under agreement number AID-OAA-A-12-00047.

Competing interests All authors have completed the ICMJE uniform disclosure form at http://www.icmje.org/coi_disclosure.pdf and declare all authors had financial support from Advancing Partners and Communities/ US. Agency for International Development for the submitted work (see Funding section above); no financial relationships with any organisations that might have an interest in the submitted work in the previous 3 years; and no other relationships or activities that could appear to have influenced the submitted work.

Ethics approval Cambodia's National Ethics Committee for Health Research (175 NECHR); Institutional Review Board at Columbia University Medical Center (AAAP2507)

Provenance and peer review Not commissioned; externally peer reviewed.

Data sharing statement No additional data are available.

Open Access This is an Open Access article distributed in accordance with the Creative Commons Attribution Non Commercial (CC BY-NC 4.0) license, which permits others to distribute, remix, adapt, build upon this work noncommercially, and license their derivative works on different terms, provided the original work is properly cited and the use is non-commercial. See: http:// creativecommons.org/licenses/by-nc/4.0/

\section{REFERENCES}

1. US Department of State, USAID. United States government action plan on children in adversity. Washington DC: A Framework for International Assistance: 2012-2017, 2012.

2. Clay R, CdeBaca L, De Cock KM, et al. A call for coordinated and evidence-based action to protect children outside of family care. Lancet 2012;379:e6-8.

3. Dozier $\mathrm{M}$, Zeanah $\mathrm{CH}$, Wallin $\mathrm{AR}$, et al. Institutional care for young children: review of literature and policy implications. Soc Issues Policy Rev 2012;6:1-25.

4. The Leiden Conference on the Development and Care of Children without Permanent Parents. The Development and Care of Institutionally Reared Children. Child Dev Perspect 2012;6:174-80.

5. McCall RB, Groark CJ, Fish L, et al. Maintaining a social-emotional intervention and its benefits for institutionalized children. Child Dev 2013;84:1734-49.

6. Merz EC, McCall RB, Groza V. Parent-reported executive functioning in postinstitutionalized children: a follow-up study. J Clin Child Adolesc Psychol 2013;42:726-33.
7. Nelson $\mathrm{CA}$, Zeanah $\mathrm{CH}$, Fox NA, et al. Cognitive recovery in socially deprived young children: the Bucharest Early Intervention Project. Science 2007;318:1937-40.

8. Bick J, Zhu T, Stamoulis C, et al. Effect of early institutionalization and foster care on long-term white matter development: a randomized clinical trial. JAMA Pediatr 2015;169:211-19.

9. Saboula NE, Hussien AA, El-Refaee EM. Occurrence and consequences of violence among orphaned institutionalized children in Menoufia Governorate. IOSR J Nurs Health Sci 2015;4:26-38

10. Kendrick A. Peer violence in provision for children in care. Child Behav Badly 2011;31:71.

11. Byrskog U, Olsson P, Essén B, et al. Violence and reproductive health preceding flight from war: accounts from Somali born women in Sweden. BMC Public Health 2014:14:892.

12. Martin F, Sudrajat T. Someone that Matters: the Quality of Care in Childcare Institutions in Indonesia. Secondary Someone that Matters: the Quality of Care in Childcare Institutions in Indonesia. 2007. http://bettercarenetwork.org/sites/default/files/attachments/ Someone\%20that\%20Matters.pdf

13. Whetten K, Ostermann J, Pence BW, et al. Three-year change in the well-being of orphaned and separated children in institutional and family-based care settings in five low-and middle-income countries. PLOS ONE 2014;9:e104872.

14. Alderson P. Competent children? Minors' consent to healthcare treatment and research. Soc Sci Med 2007;65:2272-83.

15. Petersen $A C$, Leffert $N$. Developmental issues influencing guidelines for adolescent health research: a review. J Adolesc Health 1995:17:298-305.

16. Kingdom of Cambodia. Policy on alternative care for children. Phnom Penh, Cambodia: Royal Government of Cambodia, 2006.

17. Kingdom of Cambodia. MoSVY Residential Care Inspection Report. Phnom Penh, Cambodia: Royal Government of Cambodia, 2014

18. Kendrick A, Steckley L, McPheat G. Residential childcare: learning from international comparisons. In: Taylor R, Hill M, McNeill F, Eds. Early professional development for social workers. Birmingham: British Association of Social Workers, 2011:81-7.

19. ICF Macro. Cambodia Demographic and Health Survey 2014 Phnom Penh and Calverton, MD 2015. http://dhsprogram.com/pubs/ pdf/FR312/FR312.pdf

20. Embleton L, Ayuku D, Kamanda A, et al. Models of care for orphaned and separated children and upholding children's rights: cross-sectional evidence from western Kenya. BMC Int Health Hum Rights 2014;14:9.

21. Braitstein P, Ayaya S, Nyandiko WM, et al. Nutritional status of orphaned and separated children and adolescents living in community and institutional environments in Uasin Gishu County, Kenya. PLOS ONE 2013;8:e70054.

22. Hong $Y$, Li X, Fang $X$, et al. Care arrangements of AIDS orphans and their relationship with children's psychosocial well-being in rural China. Health Policy Plan 2011;26:115-23. 